\title{
Alternative factor analysis of the investment intensity of the gross regional product of the Baikal region
}

\author{
Evgeny Filatov ${ }^{1, *}$ \\ ${ }^{1}$ Irkutsk Scientific Center of the Siberian Branch of the Russian Academy of Sciences, 664033, \\ Lermontova str., 134, Irkutsk, Russia
}

\begin{abstract}
Each effective indicator depends on numerous and various factors. The more detailed is the study of the influence of factors on the magnitude of the effective indicator, the more accurate are the results of the analysis and the evaluation of the quality of the subject of the research work. Hence, in the analysis of economic activity, an important methodological issue is the study and measurement of the influence of factors on the magnitude of the economic indicators studied. The article deals with the analysis of the investment intensity of the gross regional product of the Baikal region of the Russian Federation. The author has introduced into scientific circulation the following indicators: the investment intensity of the gross regional product, the science intensity of the gross regional product and the science return of the invested capital. The paper reveals the influence of the factors affecting the investment intensity of the gross regional product in the Baikal region of the Russian Federation and provides methodological approaches to its calculation. Also, the article presents the author's analytical and systematized statistical material for the analysis of the key indicators revealing the impact on the investment intensity of the gross regional product in the Baikal region of the Russian Federation. The paper is produced in the framework of the scientific project of the Siberian Branch of the Russian Academy of Sciences No. XI.174.1.4 "Activation of the internal development potential of regions of the resource specialization (on the example of the Baikal region)".
\end{abstract}

\section{Introduction}

Currently, in the situation of globalization, the role of the investment component in the dynamics of the economic development of different countries is significantly increasing. In this regard, the need for fundamental changes in the investment sphere caused by the shortening terms of technical re-equipment of production, connection to the world financial resources in the situation of aggravating disparities between material and financial factors of reproduction, permanent depreciation of fixed capital, destruction of the productive potential of the economy and gradual reduction of the scale of investment resources becomes urgent. In such conditions, the problem of revealing essential characteristics and the key factors

* Corresponding author: johnru3000@ rambler.ru 
determining the mode of the economic activity of investors and the reserves of growth of their investment activity deserves more attention [1].

The investment activity is an important integral part of the overall economic activity. The issue of attracting investments into economy is very acute, since they are directly related to the pace of economic growth. The factor analysis of the investment intensity of the region underlies the adoption of rational financial decisions for the management of the region, and therefore the subject matter is extremely relevant and has great practical significance.

\section{Materials and methods}

For the factor analysis of the investment intensity of the gross regional product, three indicators have been used: gross regional product (GRP), internal current expenditures for the research and development, and investment in the fixed assets. It should be taken into account that the nominal growth of GRP of the Baikal region of the Russian Federation has been influenced by the inflation. Over the past decade, even according to the Federal Statistics Service of Russia, the highest monthly inflation rates were revealed in December 2014 and January 2015 (2.62\% and 3.85\% respectively). The main factor in this increase of inflation was a significant devaluation of the ruble.

Further, based on the methods of deterministic (functional) factor analysis developed by the author [2,3], let us estimate the degree of influence of the two factors on the change of the investment intensity of the Baikal region's GRP.

The initial data for the alternative factor analysis of the investment intensity of GRP of the Baikal region is presented in Table 1.

Table 1. Baseline data for the factor analysis.

\begin{tabular}{|c|c|c|c|c|c|}
\hline No. & Indicators & $\begin{array}{c}\text { Fact } \\
\text { or } \\
\text { No. }\end{array}$ & $\begin{array}{l}2014 \\
(0) *\end{array}$ & $\begin{array}{l}2015 \\
(I) * *\end{array}$ & $\begin{array}{c}\text { Deviation } \\
(\Delta) * * *\end{array}$ \\
\hline 1 & $\begin{array}{l}\boldsymbol{V} \boldsymbol{R} \boldsymbol{P} \text { - gross regional product (GRP), } \\
\text { million rub. }\end{array}$ & & 1337651.2 & $\begin{array}{c}1 \\
466546.1\end{array}$ & 128894.9 \\
\hline 2 & $\begin{array}{l}V T Z N \text { - internal current expenditure } \\
\text { on research and development, million } \\
\text { rub. }\end{array}$ & & 5853.7 & 5596.4 & -257.3 \\
\hline 3 & $\begin{array}{l}\text { IOK - investments in the fixed assets, } \\
\text { million rub. }\end{array}$ & & 320667 & 318577 & -2090 \\
\hline 4 & $\begin{array}{l}\boldsymbol{I} \boldsymbol{E}_{V R P} \text { - investment intensity of GRP } \\
(3 / 1)=(5 * 6)\end{array}$ & & 0.239724 & 0.217229 & -0.022494 \\
\hline 5 & $\begin{array}{l}\boldsymbol{N E}_{V R P} \text { - science intensity of GRP } \\
(2 / 1)\end{array}$ & $F_{1}$ & 0.004376 & 0.003816 & -0.000560 \\
\hline 6 & $\begin{array}{l}N \boldsymbol{O}_{\boldsymbol{I K}}-\text { science return of the invested } \\
\text { capital }(3 / 2)\end{array}$ & $F_{2}$ & 54.780224 & 56.925345 & 2.145120 \\
\hline
\end{tabular}

where:

* $\mathbf{0}$ - past (basic) period (year), taken as reference base; ** $\mathbf{I}$ - reported (current) period (year);

*** $\Delta$ - change for the period, calculated as the difference between the fact and the plan $(\mathbf{I}-\mathbf{0})$.

The author introduced into scientific circulation the index of the investment intensity of GRP $\left(\boldsymbol{I E} \boldsymbol{E}_{V R P}\right)$, which is calculated as the ratio of investment in the fixed assets $(\boldsymbol{I O K})$ to the GRP.

The indicator of investment intensity of GRP consists of a product of the two factors: the science intensity of GRP and the science return of the invested capital.

The initial formula for factor analysis of the investment intensity of GRP $\left(\boldsymbol{I} \boldsymbol{E}_{V R P}\right)$ will be as follows (formula 1): 


$$
I E_{V R P}=\frac{V T Z N}{V R P} * \frac{I O K}{V T Z N}=F_{1} * F_{2}
$$

The has author introduced into scientific circulation the indicator of the science intensity of GRP $\left(\boldsymbol{N} \boldsymbol{E}_{\boldsymbol{V} R \boldsymbol{P}}\right)$, which is calculated as the ratio of the internal current expenditures on research and development (VTZN) to the size of the gross regional product (VRP). If in 2014 the science intensity of GRP of the Baikal region of the Russian Federation was $0.44 \%$, in 2015 it decreased to $0.38 \%$.

The has author introduced into scientific circulation the indicator of the science return on the invested capital $\left(\boldsymbol{N} \boldsymbol{O}_{\boldsymbol{I K}}\right)$, which is calculated as the ratio of investments in the fixed assets $(\boldsymbol{I O K})$ to the amount of domestic operating costs for research and development (VTZN). If in 2014 the science return on the invested capital in the Baikal region of the Russian Federation was 54.78, in 2015 it increased to 56.93.

The cumulative deviation by the resultant indicator $\left(\boldsymbol{\Delta I} \boldsymbol{E}_{V R P}\right)$ is determined by the formula 2:

$$
\Delta I E_{V R P}=\sum_{n=1}^{2} \Delta I E_{V R P}\left(F_{n}\right)=\Delta I E_{V R P}\left(F_{1}\right)+\Delta I E_{V R P}\left(F_{2}\right)
$$

Auxiliary data on the comparative coefficients for the factor analysis are presented in the Table 2.

Table 2. Multiple comparative coefficients by one factor.

\begin{tabular}{|c|c|c|c|}
\hline $\begin{array}{c}\text { Comparison of } \\
\text { factors }\end{array}$ & $\begin{array}{c}\text { Signs for the } \\
\text { comparative } \\
\text { coefficients }\end{array}$ & Value & \multirow{2}{*}{$\begin{array}{c}\text { The product of the } \\
\text { coefficients (value) }\end{array}$} \\
\hline $\boldsymbol{F}_{\boldsymbol{1}(\mathrm{I})} / \boldsymbol{F}_{\boldsymbol{1}(0)}$ & $\mathrm{A}_{1}$ & 0.872018 & \multirow{2}{*}{1.00} \\
\hline $\boldsymbol{F}_{\boldsymbol{I}(0)} / \boldsymbol{F}_{\boldsymbol{I}(\mathrm{I})}$ & $\mathrm{A}_{2}$ & 1.146765 & \multirow{2}{*}{1.00} \\
\hline $\boldsymbol{F}_{\boldsymbol{2}(\mathrm{I})} / \boldsymbol{F}_{\boldsymbol{2}(0)}$ & $\mathrm{A}_{3}$ & 1.039159 & \\
\hline $\boldsymbol{F}_{\boldsymbol{2}(0)} / \boldsymbol{F}_{\boldsymbol{2}(\mathrm{I})}$ & $\mathrm{A}_{4}$ & 0.962317 & \\
\hline
\end{tabular}

The author's (alternative) methods of factor analysis are presented in the Table 3 .

Method No. 1.1 (formulas 1.1-1.3 in the Table 3) is based on the difference between the effective planned indicators, which are adjusted on the comparative coefficients $\left(A_{1}\right)$.

Method No. 1.2 (formulas 1.1-1.3 in the Table 3) is based on the difference between the effective actual indicators, which is adjusted on the comparative coefficients $\left(\mathrm{A}_{4}\right)$.

Method No. 2.1 (formulas 3.1-3.3 in the Table 3) is based on the ratio of the departure of the original factor to the original plan factor multiplied by the planned performance indicator, which is adjusted on the comparative coefficient $\left(\mathrm{A}_{1}\right)$.

Method No. 2.2 (formulas 4.1-4.3, in the Table 3) is based on the ratio of the departure of the original factor to the original actual factor multiplied by the actual performance indicator, which is adjusted on the comparative coefficient $\left(\mathrm{A}_{4}\right)$.

Method No. 3.1 (formulas 5.1-5.3 in the Table 3) is based on the difference between the effective actual and planned indicators, which is adjusted on the comparative coefficients $\left(\mathrm{A}_{1}\right)$.

Method No. 3.2 (formulas 6.1-6.3 in the Table 3) is based on the difference between the effective actual and planned indicators, which is adjusted on the comparative coefficients $\left(\mathrm{A}_{4}\right)$.

Method No. 4.1 (formulas 7.1-7.3 in the Table 3) is based on the ratio of deviation of the effective factor to the difference between the effective actual and planned factors, which is 
adjusted on the comparative coefficient $\left(\mathrm{A}_{1}\right)$.

Method No. 4.2 (formulas 8.1-8.3 in the Table 3) is based on the ratio of deviation of the effective factor to the difference between the effective actual and planned factors, which is adjusted on the comparative coefficients $\left(\mathrm{A}_{4}\right)$.

Method No. 5.1 (formulas 9.1-9.3 in the Table 3) is based on the ratio of deviation of the effective factor to the difference between the actual performance factors, which is adjusted on the comparative coefficients $\left(\mathrm{A}_{1}\right)$.

Method No. 5.2 (formulas 10.1-10.3 in the Table 3) is based on the ratio of deviation of the effective factor to the difference between the planned performance factors, which is adjusted on the comparative coefficients $\left(\mathrm{A}_{4}\right)$.

Table 3. Methods of the alternative factor analysis using the comparative coefficients.

\begin{tabular}{|c|c|c|}
\hline \multirow{2}{*}{$\begin{array}{l}\text { Formula } \\
\text { Number }\end{array}$} & \multicolumn{2}{|c|}{ Formulas / Calculations } \\
\hline & Main part of the formula & Correction factors \\
\hline 1.1 & $\Delta \boldsymbol{I} \boldsymbol{E}_{\boldsymbol{V R P}}\left(\mathrm{F}_{1}\right)=\boldsymbol{I} \boldsymbol{E}_{\boldsymbol{V R P} P} 0^{*}\left(\mathrm{~A}_{1}\right)-\boldsymbol{I} \boldsymbol{E}_{\boldsymbol{V R P} 0}$ & - \\
\hline 1.2 & $\Delta \boldsymbol{I} \boldsymbol{E}_{\boldsymbol{V R P}}\left(\mathrm{F}_{2}\right)=\left(\boldsymbol{I} \boldsymbol{E}_{\boldsymbol{V R P} 0} *\left(\mathrm{~A}_{3}\right)-\boldsymbol{I} \boldsymbol{E}_{\boldsymbol{V R P} 0}\right)^{*}$ & $\mathrm{~A}_{1}$ \\
\hline 2.1 & $\Delta \boldsymbol{I} \boldsymbol{E}_{V R P}\left(\mathrm{~F}_{1}\right)=\left(\boldsymbol{I} \boldsymbol{E}_{V R P \mathrm{I}}-\boldsymbol{I} \boldsymbol{E}_{V R P \mathrm{I}} *\left(\mathrm{~A}_{2}\right)\right) *$ & $\mathrm{~A}_{4}$ \\
\hline 2.2 & $\Delta \boldsymbol{I} \boldsymbol{E}_{\boldsymbol{V R P}}\left(\mathrm{F}_{2}\right)=\left(\boldsymbol{I} \boldsymbol{E}_{\boldsymbol{V R P} \mathrm{I}}-\boldsymbol{I} \boldsymbol{E}_{\boldsymbol{V R P} \mathrm{I}} *\left(\mathrm{~A}_{4}\right)\right)^{*}$ & - \\
\hline 3.1 & $\Delta \boldsymbol{I E}_{V R P}\left(\mathrm{~F}_{1}\right)=\left(\Delta \mathrm{F}_{1} / \mathrm{F}_{10}\right) * \boldsymbol{I} \boldsymbol{E}_{V R P}$ & - \\
\hline 3.2 & $\left.\Delta \boldsymbol{I} \boldsymbol{E}_{\boldsymbol{V R P}}\left(\mathrm{F}_{2}\right)=\left(\Delta \mathrm{F}_{2} / \mathrm{F}_{20}\right) * \boldsymbol{I} \boldsymbol{E}_{\boldsymbol{V R P} 0}\right) *$ & $\mathrm{~A}_{1}$ \\
\hline 4.1 & $\Delta \boldsymbol{I} \boldsymbol{E}_{\text {VRP }}\left(\mathrm{F}_{1}\right)=\left(\left(\Delta \mathrm{F}_{1} / \mathrm{F}_{1 \mathrm{I}}\right) * \boldsymbol{I} \boldsymbol{E}_{V R P \mathrm{I}}\right) *$ & $\mathrm{~A}_{4}$ \\
\hline 4.2 & $\Delta \boldsymbol{I E}_{\boldsymbol{V R \boldsymbol { P }}}\left(\mathrm{F}_{2}\right)=\left(\Delta \mathrm{F}_{2} / \mathrm{F}_{2 \mathrm{I}}\right) * \boldsymbol{I} \boldsymbol{E}_{\boldsymbol{V R P} \mathrm{I}}$ & - \\
\hline 5.1 & $\Delta \boldsymbol{I} \boldsymbol{E}_{V R P}\left(\mathrm{~F}_{1}\right)=\left(\boldsymbol{I} \boldsymbol{E}_{V R P} \mathrm{I}^{*} \mathrm{~A}_{4}\right)-\boldsymbol{I} \boldsymbol{E}_{V R P} 0$ & - \\
\hline 5.2 & $\Delta \boldsymbol{I} \boldsymbol{E}_{V \boldsymbol{V} P}\left(\mathrm{~F}_{2}\right)=\left(\left(\boldsymbol{I} \boldsymbol{E}_{V R P \mathrm{I}} * \mathrm{~A}_{2}\right)-\boldsymbol{I} \boldsymbol{E}_{V R P}\right)^{*}$ & $\mathrm{~A}_{1}$ \\
\hline 6.1 & $\Delta \boldsymbol{I E}_{\boldsymbol{V R P}}\left(\mathrm{F}_{1}\right)=\left(\boldsymbol{I} \boldsymbol{E}_{V R P \mathrm{I}}-\left(\boldsymbol{I} \boldsymbol{E}_{V R P 0} * \mathrm{~A}_{3}\right)\right)^{*}$ & $\mathrm{~A}_{4}$ \\
\hline 6.2 & $\Delta \boldsymbol{I} \boldsymbol{E}_{V R P}\left(\mathrm{~F}_{2}\right)=\boldsymbol{I} \boldsymbol{E}_{V R P \mathrm{I}}-\left(\boldsymbol{I} \boldsymbol{E}_{V R P 0} * \mathrm{~A}_{1}\right)$ & - \\
\hline 7.1 & 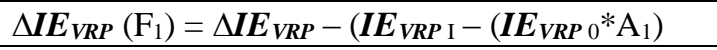 & - \\
\hline 7.2 & $\Delta \boldsymbol{I} \boldsymbol{E}_{V R P}\left(\mathrm{~F}_{2}\right)=\Delta \boldsymbol{I} \boldsymbol{E}_{V R P}-\left(\boldsymbol{E}_{V R P \mathrm{I}}-\left(\boldsymbol{E}_{V R P} 0^{*} \mathrm{~A}_{3}\right)\right) *$ & $\mathrm{~A}_{1}$ \\
\hline 8.1 & $\Delta \boldsymbol{I} \boldsymbol{E}_{V R P}\left(\mathrm{~F}_{1}\right)=\Delta \boldsymbol{I} \boldsymbol{E}_{V R P}-\left(\left(\boldsymbol{I} \boldsymbol{E}_{V R P \mathrm{I}} * \mathrm{~A}_{2}\right)-\boldsymbol{I} \boldsymbol{E}_{V R P}\right)^{*}$ & $\mathrm{~A}_{4}$ \\
\hline 8.2 & $\Delta \boldsymbol{I} \boldsymbol{E}_{V R P}\left(\mathrm{~F}_{2}\right)=\Delta \boldsymbol{I} \boldsymbol{E}_{V R P}-\left(\left(\boldsymbol{I} \boldsymbol{E}_{V R P}{ }_{\mathrm{I}} * \mathrm{~A}_{4}\right)-\boldsymbol{I} \boldsymbol{E}_{V R P}\right)$ & - \\
\hline 9.1 & $\Delta \boldsymbol{I} \boldsymbol{E}_{V R P}\left(\mathrm{~F}_{1}\right)=\Delta \boldsymbol{I} \boldsymbol{E}_{V R P}-\left(\boldsymbol{I} \boldsymbol{E}_{V R P \mathrm{I}}-\left(\boldsymbol{I} \boldsymbol{E}_{V R P \mathrm{I}} * \mathrm{~A}_{4}\right)\right)$ & - \\
\hline 9.2 & $\Delta \boldsymbol{I} \boldsymbol{E}_{V R P}\left(\mathrm{~F}_{2}\right)=\Delta \boldsymbol{I} \boldsymbol{E}_{V R P}-\left(\boldsymbol{I} \boldsymbol{E}_{V R P \mathrm{I}}-\left(\boldsymbol{I} \boldsymbol{E}_{V R P \mathrm{I}} * \mathrm{~A}_{2}\right)\right)$ & $\mathrm{A}_{1}$ \\
\hline 10.1 & $\Delta \boldsymbol{I} \boldsymbol{E}_{V R P}\left(\mathrm{~F}_{1}\right)=\Delta \boldsymbol{I} \boldsymbol{E}_{V R P}-\left(\left(\boldsymbol{I} \boldsymbol{E}_{V R P} 0_{0} * \mathrm{~A}_{3}\right)-\boldsymbol{I} \boldsymbol{E}_{V R P}\right)^{*}$ & $\mathrm{~A}_{4}$ \\
\hline 10.2 & $\Delta \boldsymbol{I} \boldsymbol{E}_{V R P}\left(\mathrm{~F}_{2}\right)=\Delta \boldsymbol{I} \boldsymbol{E}_{V R P}-\left(\left(\boldsymbol{I} \boldsymbol{E}_{V R P} 0^{*} \mathrm{~A}_{1}\right)-\boldsymbol{I} \boldsymbol{E}_{V R P} 0\right)$ & - \\
\hline
\end{tabular}

\section{Results}

The result by the methods $1.1,2.1,3.1,4.1,5.1$ is presented in the Table 4 , the result by the methods 1.2, 2.2, 3.2, 4.2, 5.2 is presented in the Table 5.

Table 4. Result by the methods 1.1, 2.1, 3.1, 4.1, 5.1.

\begin{tabular}{|c|l|c|l|c|}
\hline No. & Main part of the formula & \multicolumn{2}{|c|}{ Correction coefficients } & Result \\
\hline 1 & $\Delta I E_{V R P}\left(\mathrm{~F}_{1}\right)=-0.030680$ & - & & -0.030680 \\
\hline 2 & $\Delta I E_{V R P}\left(\mathrm{~F}_{2}\right)=0.009387$ & 0.872018 & $\mathrm{~A}_{1}$ & 0.008186 \\
\hline & $\mathbf{- 0 . 0 2 1 2 9 3}$ & & $\mathbf{- 0 . 0 2 2 4 9 4}$ \\
\hline
\end{tabular}


Table 5. Result by the methods 1.2, 2.2, 3.2, 4.2, 5.2.

\begin{tabular}{|c|c|c|c|c|}
\hline № & Main part of the formula & \multicolumn{2}{|c|}{ Correction coefficients } & Result \\
\hline 1 & $\Delta \boldsymbol{I} \boldsymbol{E}_{\text {VRP }}\left(\mathrm{F}_{1}\right)=-0.031882$ & 0.962317 & $\mathrm{~A}_{4}$ & -0.030680 \\
\hline \multirow[t]{2}{*}{2} & $\Delta \boldsymbol{I} \boldsymbol{E}_{\text {VRP }}\left(\mathrm{F}_{2}\right)=0.008186$ & - & & 0.008186 \\
\hline & -0.023696 & & & -0.022494 \\
\hline
\end{tabular}

As it is seen from the final result of the Tables 1, 4, 5, the goal of the analysis is achieved - the determination of the influence of factors is identified without deviations.

Based on the results of the analysis, the following factors influenced the change in the investment intensity of GRP $\left(\Delta \boldsymbol{I} \boldsymbol{E}_{V R P}\right)$ of the Baikal region of the Russian Federation in the amount of $-2.2494 \%$ :

- decrease in the science intensity of GRP of the Baikal region of the Russian Federation $\left(\mathrm{F}_{1}\right)$ by -0.00056 reduced the investigated indicator by $-3.068 \%$;

- increase in science return of the invested capital in the Baikal region of the Russian Federation $\left(\mathrm{F}_{2}\right)$ by 2.145120 increased the investigated indicator by $+0.8186 \%$.

According to the results of the analysis, it is clear that in 2015, compared to 2014, the investment intensity of the economy of the Baikal region of the Russian Federation decreased by $2.25 \%$. Formally, reducing the investment intensity of GRP is a positive effect, because this in turn leads to the increase in the investment return of GRP (investment return GRP $\left(I O_{V R P}\right)$ - the inverse measure of the investment intensity of GRP: $\left.I \boldsymbol{O}_{V R P}=1 / \boldsymbol{I} \boldsymbol{E}_{V R P}\right)$.

\section{Discussion}

The issue of the effectiveness of a business entity activity has always occupied an important place among the pressing problems of economic science. This issue is especially topical at the present stage of the economic development due to the increase of competition, business globalization and the growth of the entrepreneurial risks.

Data on the investment intensity, both for the Russian Federation as a whole, and for the Baikal region in particular demonstrates a fairly low index (about $21 \%$ ). Therefore, about a fifth in one ruble of GRP is invested in the fixed assets. In turn, low investment intensity contributed to the stagnation and decreased competitiveness of the Russian economy.

At the same time, without growth in the assets or renewal of their composition, commercial organizations cannot successfully develop in the long run. Investment policy of companies is an important part of their overall development strategy.

\section{Conclusion}

The economic growth and investments are interrelated and interdependent. The investments create a material basis for the sustainable development, the results of which, in turn, are a source of funds for the new capital investments. Investing is the main form of practical implementation of economic strategy.

Attracting investments to the region gives it additional competitive advantages and is often a powerful means of growth. The main and most common goal of attracting investments is to increase the efficiency of a business entity.

Decision-making in the economic environment presupposes a comprehensive analysis of information in retrospect, and current and prospective states of socio-economic dynamics of 
social development. To obtain this information, a comprehensive study of the dynamic characteristics of development of the economic system is needed, which indicates the influence of specific factors and the manifestation of the corresponding trends. In its development, the economic system goes through the stages of ups and downs, determined by the general laws of its development. In this regard, the development of the economic system should be viewed as a cyclical process [4].

\section{References}

1. N. A. Pavlyuk, Bulletin of the Gomel State Technical University named after B. Y. Sukhoy, 85-92, (2004)

2. E. A. Filatov, Methodology of evaluation and analysis of the performance of commercial organizations (2015)

3. E. A. Filatov, Methods of deterministic (functional) factor analysis (2011)

4. A. V. Shchavinsky, Evolution of the theory of wave macrodynamics of economic development: nature of cycles, imperatives of management, projections (Candidate of Sciences Dissertation, 2008) 